\title{
Martin Rueff, Différence et Identité. Michel Deguy, situation d'un poète lyrique à l'apogée du capitalisme culturel
}

\section{Fabio Scotto}

\section{(2) OpenEdition \\ Journals}

\section{Edizione digitale}

URL: http://journals.openedition.org/studifrancesi/5770

DOI: $10.4000 /$ studifrancesi. 5770

ISSN: 2421-5856

\section{Editore}

Rosenberg \& Sellier

\section{Edizione cartacea}

Data di pubblicazione: 1 septembre 2011

Paginazione: 458-459

ISSN: 0039-2944

\section{Notizia bibliografica digitale}

Fabio Scotto, «Martin Rueff, Différence et Identité. Michel Deguy, situation d'un poète lyrique à l'apogée du capitalisme culturel», Studi Francesi [Online], 164 (LV | II) | 2011, online dal 30 novembre 2015,

consultato il 09 janvier 2021. URL: http://journals.openedition.org/studifrancesi/5770 ; DOI: https:// doi.org/10.4000/studifrancesi.5770

Questo documento è stato generato automaticamente il 9 janvier 2021.

\section{cc) $($ ) $\ominus$}

Studi Francesi è distribuita con Licenza Creative Commons Attribuzione - Non commerciale - Non opere derivate 4.0 Internazionale. 


\title{
Martin Rueff, Différence et Identité. Michel Deguy, situation d'un poète lyrique à l'apogée du capitalisme culturel
}

\author{
Fabio Scotto
}

\section{NOTIZIA}

MARTIN RUEFF, Différence et Identité. Michel Deguy, situation d'un poète lyrique à l'apogée du capitalisme culturel, Paris, Hermann, 2009 («Le Bel Aujourd’hui»), 459 pp.

1 Nella premessa (Avertissement, pp. 7-36) a questo suo cospicuo e densissimo studio non facilmente riassumibile per l'estrema analiticità che lo caratterizza, Martin Rueff, poeta, traduttore e professore all'Università di Ginevra parte dalla constatazione della difficoltà che ha la poesia odierna ad incontrare i lettori, nonostante la grande vitalità che la caratterizza, nella società dello "spettacolo" che è quella dell'apogeo del «capitalismo culturale» (p. 12). Ciò è particolarmente vero per un poeta complesso $\mathrm{e}$ ritenuto difficile come Michel Deguy, tra gli ineludibili dell'attuale panorama, proprio in quanto poeta e filosofo, quindi autore di una poesia inscindibile dall'opera del pensiero che la abita e la vivifica. L'A. si propone di "situarlo" per situare la lingua della poesia nella società d'oggi, attraverso l'apprezzamento di quanto persiste della poesia alla fine del poème, della disperazione che lo abita. L'architettura del suo studio si prefigge quindi di affrontare il rapporto fra «différence» e «identité» per stabilire la coerenza profonda dell'opera di Deguy attraverso la poesia, la poetica e il poème (p. 33).

Articolato secondo un Indice argomentativo che non si limita a elencare gli argomenti, ma sviluppa sugli stessi un discorso riassuntivo, il volume si compone di cinque capitoli. Il primo Différence et identité (pp. 37-58) è incentrato sulla "poétique dialectique» di Deguy, il cui senso è più adorniano che hegeliano, in una terra sempre 
più preda di quello che egli chiama con un neologismo il «géocide» che la rende inabitabile (p. 56). Ne consegue, nel secondo capitolo Le Culturel (pp. 59-96), la sublimazione della cultura che è il «culturel» vissuto come un feticcio dell'età della tecnica il quale ha soppiantato il mito e "disidentifica" la cosa (p. 60) per farne l'immagine accecante che preclude l'esperienza e produce attraverso la tecnologia l'apparenza e l'illusione dell'essere; ne è paradigma il turismo, con la sua antropologia sociale fondata su un mimetismo che annulla la differenza.

3 Nel terzo capitolo La Poésie (pp. 97-192), Rueff mostra il rapporto fra poesia e fenomenologia nell'opera di Deguy poeta-fenomenologo attraverso una disamina circostanziata dei meccanismi di figurazione e decostruzione della retorica in una sorta di sillogistica lirica "diférentielle» che si articola in un'estetica, in un'erotica e in una pronominale fraternità del "comme-un» come permanenza della singolarità nell'umanità del "noi". Il quarto capitolo La Poétique profonde (pp. 193-230) situa la ricerca di Deguy nell'ambito della storia della poetica, ricerca che, come scrive Max Loreau, «repose sur l'intégration progressive de la poétique dans la poésie» (p. 194) e mira a una progressiva rivelazione della verità. È nel quinto capitolo Le Poème (pp. 231-406), il più vasto, che l'A. esplora il lirismo di Deguy come forma di «attachement» in relazione al pensiero di Kant e di Derrida e alla poetica della morte; si rivela così la singolarità della sua cronotopia e il suo rapporto con l'immagine e la materia fonica $\mathrm{e}$ grafica del testo, la sua grammatologia appercettiva. Gli Annexes studiano la specificità sintattico-formale della prosa di Deguy e la sua poetica della traduzione, fondata su un rifiuto del messianismo derridiano attraverso una sintassi del nome inserito nel corpo della frase che si distingue dalla più semanticistica nozione di terza lingua di W. Benjamin (pp. 439-440). In appendice un Index (pp. 441-450) e una Table des gloses (p. 451). 